\title{
RESUMEN.
}

Dentro del contexto de la ley 19.913 referida al lavado de dinero en Chile, gran cantidad de entidades públicas y privadas se vieron obligadas, en distintos ámbitos, a cumplir con la nueva legislación, razón por la cual el propósito de esta investigación es analizar el efecto de la aplicación de esta ley en una institución bancaria en el marco de sus actividades diarias. La metodología empleada corresponde a una cualitativa con un alcance de comprehensión, la que se llevó a cabo realizando entrevistas al agente de sucursal, ejecutivo de cuentas, encargado de operaciones y personal de ventas de la institución. El resultado del análisis indica que el Banco realiza procedimientos para prevenir, controlar y detectar el delito del lavado de dinero por medidas propias y no por el surgimiento de la ley, indicando que el efecto no es de importancia económica, ya que ellos invierten en seguridad del negocio por el riesgo que involucra, y a la vez cumplen con todas las obligaciones descritas en la ley, resguardando así su imagen y seguridad.

Palabras Claves: Lavado de Dinero, Instituciones Financieras, Ley 19.913.

\section{ANÁLISIS DEL EFECTO DE LA APLICACIÓN DE LA LEY 19.913 DE LAVADO DE ACTIVOS EN UNA INSTITUCIÓN FINANCIERA.}

Viviana Macarena Labra Castro

\section{ANALYSIS OF THE EFFECT OF THE ENFORCEMENT OF LAW 19.913 ABOUT MONEY LAUNDERING IN A BANK}

\begin{abstract}
.
Within the context of Law 19.913 which refers to money laundering in Chile, the majority of the public and private entities were obliged to fulfill the new legislation in different domains. That is the reason why the aim of this research is to analyze the effect of the enforcement of this law in a bank in the framework of its daily activities.A comprehensive qualitative methodology was used, and it was carried out by making interviews to the branch agent, the account executive, the operation manager and sales ' personnel of the institution. The result of the analysis indicates that the bank, on its own, adopts procedures to prevent, control and detect the money laundering offense, and not because of the emergence of the law. Thus, showing that the law effect is of no economical importance due to the fact that they invest in the business security because of the risk it involves, and at the same time they fulfill all the obligations described in the law, protecting their image and security
\end{abstract}

Key Words: Money Laundering, Banks, Law 19.913.

1 Alumna Tesista de la Carrera de Auditoría de la Universidad de Valparaíso, teniendo como profesor guía a la Dra. Karime Chahuán Jiménez. 
Revista de Investigación Aplicada en Ciencias Empresariales 


\section{PLANTEAMIENTO DEL PROBLEMA}

Constantemente se puede apreciar una fuerte presencia en los medios de comunicación y la opinión mundial de temas como el lavado de dinero (Dawes y Villanueva, 2010), en Chile a finales del 2003 se publicó y promulgó la Ley № 19.913 que crea la unidad de análisis financiero y modifica diversas disposiciones en materia de lavado y blanqueo de activos, la cual con el paso de los años ha sido actualizada y modificada; (Ley $N^{\circ} 20.818$ ) perfeccionando los mecanismos de prevención, detección, control, investigación y juzgamiento de este delito. En donde se le otorga mayores obligaciones a entidades del mundo privado y entidades financieras como lo es el reporte de operaciones sospechosas (Ley 19.913, 2015).

La Unidad de Análisis Financiero señala que el lavado de activos busca ocultar o disimular la naturaleza, origen, ubicación, propiedad 0 control de dinero y/o bienes obtenidos ilegalmente y que generalmente está vinculado a actividades como el tráfico de drogas, corrupción y evasión (UAF, 2003). Por lo mismo está bajo la mira de entidades como La Superintendencia de Bancos e Instituciones Financieras y Superintendencia de Valores y Seguros. Es así, que bajo esta ley tanto personas naturales como jurídicas estarán obligadas a informar sobre operaciones sospechosas que adviertan en el ejercicio de sus actividades y a una serie de otros deberes (UAF, 2003), en donde el mejor ejemplo es una empresa bancaria de reconocimiento nacional e internacional que se ve afectado por esto a diario en el desarrollo de sus funciones.

El propósito de la investigación es analizar el efecto que ha tenido la aplicación de la Ley № 19.913 en una de las entidades obligadas, específicamente en un banco chileno con sucursal en la región de Valparaíso, el cual presta una serie de servicios financieros a las personas y ayuda a realizar gran cantidad de transacciones.

\section{MARCO TEÓRICO}

\section{Antecedentes Generales}

La Unidad de Análisis Financiero, encargada de prevenir e impedir la utilización del sistema financiero y de otros sectores, para la comisión de los delitos de lavado de activos y financiamiento del terrorismo en Chile, señala que estos implican daños tangibles e intangibles para la sociedad en su conjunto, los que en su expresión más grave redundan en amenazas a la estabilidad económica y financiera de los países y en efectos perniciosos para la transparencia y gobernabilidad de los 
Estados. Por otro lado para detener estas prácticas se requieren medidas eficaces en prevención, detección y disuasión del delito, como asimismo en su persecución penal, en forma coordinada, a nivel nacional e internacional. Sin embargo, esta estrategia es insuficiente si no cuenta con la activa colaboración del sector privado. (UAF, 2003). A continuación se detallarán temas relacionados al lavado de dinero, en especial el marco jurídico que regula estas materias en Chile, así como características principales para conocer este delito que afecta a las organizaciones.

\section{Concepto de lavado de dinero}

"El lavado de activos (LA) busca ocultar o disimular la naturaleza, origen, ubicación, propiedad o control de dinero y/o bienes obtenidos ilegalmente. Implica introducir en la economía activos de procedencia ilícita, dándoles apariencia de legalidad al valerse de actividades lícitas, lo que permite a delincuentes y organizaciones criminales disfrazar el origen ilegal de su producto, sin poner en peligro su fuente." (UAF, 2003)

\section{Origen del lavado de dinero}

Respecto al origen que puede tener este delito, la Secretaria de prevención de lavado de dinero o bienes de Paraguay, menciona que se han practicado ciertas formas de lavado de dinero desde que surgió la necesidad de ocultar la existencia de ciertas transferencias financieras por razones ya sean políticas, comerciales 0 jurídicas. Hay registros de esta actividad que datan de la edad media con los mercaderes y prestamistas que hacían desaparecer los ingresos de los intereses cobrados para luego en los años 1600 seguir con los piratas. También señala que los motivos podían ser muy diversos, como por ejemplo: grupos de delincuentes callejeros trataban de buscar un origen aparentemente legítimo para el dinero que sus negocios turbios generaban, evitar despertar el interés de competidores envidiosos 0 evitar la posibilidad de ser inculpados por evasión de impuestos. Para lograr estas metas, estas bandas criminales adquirían negocios de servicios pagaderos en metálico. Frecuentemente optaban por comprar lavanderías, servicios de lavado de coches y otros negocios. (SEPRELAD, 1997)

La Unidad de Análisis Financiero se refiere al lavado de activos señalando que "generalmente se identifica el narcotráfico como el principal delito base del lavado de activos. No es el único: el LA también se puede originar en la venta ilegal de armas, la trata de blancas, las redes de prostitución, la malversación de fondos 
públicos, el uso malicioso de información privilegiada, el cohecho, el fraude informático y el terrorismo, entre otros delitos. Todos ellos producen beneficios y ganancias mal habidas, que crean incentivos para que se intente legitimarlas." (UAF, 2003) Hace también referencia a los riesgos que involucra el lavado de activos destacando los siguientes:

- Sociales: al favorecer indirectamente la criminalidad, permitiendo al delincuente legitimar el producto del delito.

- Económicos: al producir distorsiones en los movimientos financieros e inflar industrias o sectores más vulnerables.

- Financieros: al introducir desequilibrios macroeconómicos y dañar la integridad del sistema financiero.

- Reputacionales: por la pérdida de prestigio, crédito y/o reputación tanto de entidades financieras como no financieras y de sus profesionales. (UAF, 2003).

"En Chile en la actualidad se ha tratado de encontrar el origen del lavado de dinero y se ha llegado a la conclusión que los principales delitos vinculados con lavado de activos, lidera el tráfico de drogas con un 48\%, seguido de corrupción con un 19\% y evasión fiscal con un 16,6\%." (Dawes y Villanueva, 2010; 39)

\section{Formas de materializar el lavado de dinero}

La necesidad de blanquear dinero surge cuando no es posible justificar su procedencia porque es la contraprestación a la ejecución de una actividad delictiva. Ello obliga a quienes acumulan grandes cantidades de dinero de origen ilícito a encontrar las vías que le permitan introducirlo en lo que podría llamarse "circuito monetario", de modo que puedan obtener una rentabilidad sin justificar su procedencia. Junto con este propósito, se encuentra muchas veces el de ocultar la identidad del verdadero propietario de los fondos que se pretenden lavar, con la finalidad de dificultar la persecución penal y asegurar la impunidad de los participantes en los delitos que han generado el dinero sucio. (Toso, 2008; 2) Estas formas de materializar el lavado de dinero han sido estudiadas por distintos autores, Ángela Toso en su investigación de Blanqueo de Capitales explica que se puede sostener que el dinero en el proceso de blanqueo suele seguir distintas etapas con independencia de la complejidad de la operación que se trate, las que denominó "colocación", "enmascaramiento" e "integración”, respectivamente. Estas tres fases pueden llevarse a cabo separada o simultáneamente, aunque a menudo 
se superponen. "La elección de alguna de ellas por parte de los delincuentes, dependerá, entre otros factores, de sus necesidades, de los mecanismos de lavado de activos disponibles en un determinado momento, así como de las vulnerabilidades existentes en el ordenamiento jurídico en que se pretende llevar a cabo la(s) operación(es) de reciclaje." (Toso, 2008; 3)

"El objetivo de quienes blanquean capitales en la primera de las etapas indicadas (colocación), es deshacerse materialmente de las importantes sumas en efectivo que genera su actividad delictiva. Ello se lleva a cabo, normalmente, trasladando materialmente el dinero a una localidad distinta de aquella en que se recaudó, e introduciéndolo a continuación, en establecimientos financieros como bancos, casas de cambio o en otro tipo de negocios de muy variada condición." (Toso, 2008; 3)

"La segunda etapa del proceso de blanqueo, denominada enmascaramiento 0 estratificación, tiene como objetivo desligar los dineros ilícitos de su origen, generando para ello un complejo sistema de amontonamiento de transacciones financieras encaminado a borrar la huella contable de tales fondos ilícitos. Algunos de los métodos utilizados en esta fase son:

a) La conversión del dinero en metálico en otros instrumentos o medios de pago;

b) La transferencia electrónica o telegráfica de fondos depositados en un banco a otras cuentas situadas en zonas geográficas diversas." (Toso, 2008; 3)

"Por último la tercera y última etapa que se puede reconocer en el proceso de lavado de activos se denomina integración y consiste en conferir una apariencia definitiva de legalidad a un patrimonio de origen criminal, situando los fondos blanqueados en la economía de tal forma que, integrándose en el sistema bancario, aparecen como producto de una actividad comercial normal. Llegados a este estado, los dineros de origen delictivo son ya muy difíciles de detectar. "(Toso, 2008; 4)

"A menos que se haya podido seguir su rastro a través de las etapas anteriores, resultará sumamente complejo distinguir los capitales de origen ilegal de los de origen legal. Algunos de los métodos utilizados en esta fase son los siguientes:

a) Venta de bienes inmuebles;

b) Constitución de sociedades "pantalla" y préstamos simulados; y

c) Generación de facturas falsas de importación-exportación. 
Existe consenso en señalar que la mayor posibilidad de detectar el dinero sucio se encuentra en la fase de "colocación" precedentemente descrita, de modo que la mayoría de las medidas de prevención están orientadas hacia esta etapa del blanqueo. Ello por cuanto, en las restantes fases se hace necesario un esfuerzo adicional por parte de las autoridades para rastrear el origen delictivo de los fondos, en tanto estos han sido sometidos previamente por los delincuentes a diversas técnicas que dificultan esta tarea. (Toso, 2008; 4)

Según especialistas, el modus operandi del encubrimiento financiero se materializa generalmente a través de las siguientes actividades:

- Compras de bienes de consumo como automóviles, casa, joyas, obras de arte, etc.

- Exportaciones subrepticias o ilegales del dinero, lo cual es secundado por el depósito del mismo en cuentas cifradas en el extranjero o la apertura de empresas de intercambio de divisas, de exportación, etc.

- Conversión de divisas: se trata de llevar los billetes de baja denominación y difícil transportación a medios de pago cómodos, como bonos de caja, cheques de gerencia, cheques de viajero o cuentas corrientes múltiples.” (Gómez, 1997)

En Chile, según la Superintendencia de Bancos e Instituciones Financieras, una de las entidades más importantes dentro de la prevención del lavado de dinero, son las instituciones bancarias, ya que por la naturaleza de sus funciones, pueden ser utilizadas para depositar y transferir fondos, cuyo objetivo sea intentar legitimar activos provenientes del narcotráfico 0 de otras operaciones ilícitas, o que sean utilizados, por ejemplo, para obtener materiales y/u otros elementos logísticos necesarios para el financiamiento del terrorismo. A través de sus circulares además señala que se debe tener en cuenta que tanto el lavado de activos como el financiamiento del terrorismo dan origen a riesgos de reputación, operativos y legales a que puede exponerse una entidad financiera, comprometiendo su estabilidad y viabilidad económica. (SBIF- Circular №3.435, 2008)

\section{Auditoría en el Lavado de dinero}

"El auditor para poder reconocer cuando se encuentra frente a una institución con indicios asociados al Lavado de Dinero, debe tener presente en su análisis previo dos importantes antecedentes, como lo son las características de las organizaciones con riesgos de Lavado de Dinero y los componentes de los Estados 
Con respecto al contador público la Unidad de Información y Análisis Financiero de Colombia indica la importancia que debe tener su escepticismo profesional cuando se establecen las relaciones comerciales y en el momento de revisar las transacciones entre partes relacionadas, sobre todo si parecen tener un sentido comercial cuestionable desde el punto de vista del negocio. "Las entidades e individuos corruptos deben darse cuenta de que la contabilidad constituye una barrera contra la corrupción. Sobre todo, cada contador como individuo debe asegurarse de que su propia conducta refleje un compromiso firme con la verdad y la honestidad en los informes financieros." (UIAF, 2007).

Junto con el papel del contador aparece la auditoría forense como una ayuda a la contaduría para la investigación, detección y prevención de crímenes económicos y financieros como el lavado de activos. Cano y Lugo (2005) definen en términos de investigación contable y de procedimientos de auditoría, a la auditoría forense como "una auditoría especializada en descubrir, divulgar y atestar sobre fraudes y delitos en el desarrollo de las funciones públicas y privadas”, “... la ciencia que permite reunir y presentar información financiera, contable, legal, administrativa e impositiva, para que sea aceptada por una Corte 0 un juez en contra de los perpetradores de un crimen económico, como en el de lavado de activos" (Cano \& Lugo, 2005; 16)

Por último, la auditoría también forma parte del proceso de prevención del lavado de activos y financiamiento del terrorismo, ya que según entidades públicas deben ser periódicamente evaluado por la auditoría interna de la institución, sobre la base de procedimientos definidos por la entidad, aprobados por la alta administración y de aceptación general." (SBIF- Circular №3.435, 2008)

\section{Organizaciones a nivel mundial relacionadas al lavado de dinero}

"Cabe mencionar que las directrices contra el lavado de activos y financiamiento del terrorismo se han venido construyendo a partir de la adopción de una reglamentación internacional. Esta reglamentación que, en lo principal, es atingente al sector bancario, está plasmada en las recomendaciones del Grupo de Acción Financiera Internacional (GAFI) y en el documento de debida diligencia con la clientela de los bancos, del Comité de Supervisión Bancaria de Basilea. También debe considerarse en ese sentido el trabajo desarrollado por la Asociación de Bancos e Instituciones Financieras de Chile A.G., materializado en el "Manual para la prevención del blanqueo de capitales". (SBIF- Circular N³.435, 2008). 
Por lo tanto, con el objeto de combatir este delito financiero, se han creado instituciones, normativas y legislaciones, cuyo funcionamiento es estrictamente seguido por los distintos actores de la sociedad. Así como también, las autoridades locales y de otros países han expandido la definición para incluir dinero derivado de otros delitos, crímenes y actividades ilegítimas, tales como el financiamiento del terrorismo. Esta amplitud del alcance parece hacer más dificultosa la tarea a los gobiernos, reguladores, entidades y dirigentes para detectarlo y combatirlo. (Dawes y Villanueva, 2010)

Algunas de estas instituciones son:

1) GAFI: "El Grupo de Acción Financiera Internacional es un organismo intergubernamental cuyo propósito es el desarrollo y la promoción de políticas, en los niveles nacional e internacional, para combatir el Lavado de Activos y la Financiación del Terrorismo. Promoviendo el fortalecimiento de las políticas nacionales en la materia y la profundización de los mecanismos de cooperación entre los países miembros." (UIF, 2015)

"En 1990, dicho organismo elaboró por vez primera el texto denominado "Las Cuarenta Recomendaciones del GAFI" sobre blanqueo de capitales, cuya última versión es del año 2003. También adoptó, en 2001, las denominadas Recomendaciones especiales sobre la financiación del terrorismo, cuya última actualización corresponde al año 2004. Ambos instrumentos han sido de vital importancia para la elaboración de la regulación sobre lavado de activos, por ejemplo, a nivel europeo y también para el ordenamiento jurídico chileno." (Toso, 2008; 2) Sus principales funciones son:

- Establecer estándares para el combate de LA/FT;

- Asegurar su implementación en los países miembros;

- Estudiar las técnicas y tipologías de lavado de activos y financiamiento del terrorismo; y

- Realizar actividades de asistencia destinadas a divulgar los estándares recomendados en todo el mundo (UIF, 2000)

2) GAFILAT: "El Grupo de Acción Financiera de Latinoamérica es el organismo regional homólogo de GAFI, cuyos 12 países miembros, incluyendo a Chile adoptaron los nuevos estándares. Los principales cambios contemplan: 
- La integración de los estándares anti LA/FT en solo 40 recomendaciones (en lugar de los 49 anteriores).

- La incorporación del combate al financiamiento de la proliferación de armas de destrucción masiva, a través de la aplicación de las sanciones financieras del Consejo de Seguridad de las Naciones Unidas.

- Mayor transparencia para dificultar a los criminales y terroristas el ocultamiento de sus identidades 0 bienes a través de personas jurídicas 0 acuerdos.

- Requisitos más estrictos para el tratamiento de las Personas Expuestas Políticamente (PEP).

- Inclusión de los delitos fiscales como delitos de lavado de activos.

- Profundización del enfoque basado en el riesgo, orientado a que los países y el sector privado usen en forma más eficiente sus recursos, centrándose en áreas de mayor vulnerabilidad.

- Recomendaciones de mayor cooperación internacional eficaz, incluyendo el intercambio de información entre las autoridades competentes, el desarrollo de investigaciones conjuntas, y la localización, congelamiento y confiscación de bienes ilícitos." (UIF, 2000)

\section{3) UNIDAD DE ANÁLISIS FINANCIERO (UAF):}

“En Chile, la Ley № 19.913, publicada en el Diario Oficial el 18 de diciembre de 2003, creó la Unidad de Análisis Financiero (UAF) y modificó el Código Penal en materia de lavado o blanqueo de activos. Lo anterior, ante la necesidad de contar en el país con una institución especializada, y con funciones apropiadas para prevenir y controlar el lavado o blanqueo de activos, con el objetivo de impedir la utilización del sistema financiero y de otros sectores de la actividad económica para legitimar ganancias ilícitas. " (UAF, 2003)

Tiene las siguientes atribuciones y funciones:

a) Solicitar, verificar, examinar y archivar la información a que se refiere el artículo $3^{\circ}$ ley 19.913. 
b) Solicitar a cualquiera de las personas naturales 0 jurídicas contempladas en el artículo $3^{\circ}$ de la ley 19.913, los antecedentes que con ocasión de la revisión de una operación sospechosa previamente reportada a la Unidad o detectada por ésta en ejercicio de sus atribuciones, resulten necesarios y conducentes para desarrollar 0 completar el análisis de dicha operación y los que deba recabar de conformidad con la letra g).

c) Disponer exámenes periciales, los que podrá encomendar a instituciones públicas o privadas.

d) Organizar, mantener y administrar archivos, base de datos y registros. (UAF, 2003)

\section{Marco jurídico de la prevención del blanqueo de capitales en el ordenamiento jurídico chileno}

"El marco jurídico chileno para las actividades desarrolladas por las entidades bajo la supervisión de la Superintendencia, está conformado por las disposiciones contenidas en la Ley General de Bancos y por instrucciones de este Organismo. No obstante, las entidades bancarias también deben cumplir con otras disposiciones de carácter general emanadas de leyes de la República, como es el caso de la Ley $N^{\circ}$ 19.913. Por su parte, dicha regulación se ve complementada por aquella de carácter sectorial, emanada, por ejemplo, de organismos como la Superintendencia de Valores y Seguros, la Superintendencia de Bancos e Instituciones Financieras, la de Casinos de Juego y la de AFP. A lo anterior habrá que agregar la actividad desplegada en este ámbito por la Unidad de Análisis Financiero (UAF)." (Toso, 2008; 10)

\section{Ley $\mathrm{N}^{\circ} 19.913$}

"La Ley № 19.913 fue modificada el 31 de agosto de 2006 con la entrada en vigencia de la Ley $^{\circ} 20.119$ que, entre otras materias, amplió el universo de entidades obligadas a informar a la UAF sobre operaciones sospechosas de lavado de activos (LA), y estableció sanciones administrativas, de acuerdo a la gravedad y reiteración de los hechos materia de la infracción cometida. El 18 de febrero de 2015, en tanto, se publicó en el Diario Oficial la Ley № 20.818 que introdujo importantes modificaciones a la Ley $N^{\circ} 19.913$, al ampliar el catálogo de delitos base de LA, incorporar a todo el sector público como sujeto obligado a informar operaciones sospechosas de LA y financiamiento del terrorismo, y modificar el 
umbral de los Reportes de Operaciones en Efectivo (ROE) desde UF 450 a USD 10.000, entre otros aspectos." (UAF, 2015)

Por su parte, las medidas de prevención de este delito se concretan, en las disposiciones contenidas en el párrafo segundo de la Ley, estas normas pretenden imponer obligaciones a operadores económicos que desarrollan su actividad, fundamentalmente, en el ámbito financiero, mas no exclusivamente en este. (Toso, 2008; 10)

"Las medidas de prevención de lavado de activos establecidas por la Ley 19.913 han de ser adoptadas por determinadas personas, naturales 0 jurídicas, que desarrollan ciertas actividades que el legislador ha considerado sensibles al blanqueo de capitales. Estos son los que denominaremos "sujetos obligados", y se encuentran contemplados en el artículo 3 inciso primero de dicho instrumento legal." (Toso, 2008; 12)

En cuanto a las personas obligadas, según el artículo $3^{\circ}$ de esta ley, correspondientes a las personas naturales y jurídicas que se señalan a continuación, estarán obligadas a informar sobre operaciones sospechosas que adviertan en el ejercicio de sus actividades:

- $\quad$ "Los bancos e instituciones financieras; empresas de factoraje; empresas de arrendamiento financiero; las empresas de securitización; las administradoras generales de fondos y las sociedades que administren fondos de inversión privados; las casas de cambio y otras entidades que estén facultadas para recibir moneda extranjera; las emisoras y operadoras de tarjetas de crédito; las empresas de transferencia y transporte de valores y dinero; las bolsas de valores y las bolsas de productos, así como cualquier otra bolsa que en el futuro esté sujeta a la supervisión de la Superintendencia de Valores y Seguros; Ios corredores de bolsa; los agentes de valores; las compañías de seguros; los administradores de fondos mutuos; los operadores de mercados de futuro y de opciones; las sociedades administradoras y los usuarios de zonas francas; los casinos, salas de juego e hipódromos; los titulares de permisos de operación de juegos de azar en naves mercantes mayores, con capacidad de pernoctación a bordo, y que tengan entre sus funciones el transporte de pasajeros con fines turísticos; los agentes de aduana; las casas de remate y martillo; los corredores de propiedades y las empresas dedicadas a la gestión inmobiliaria; Ios notarios; los conservadores las administradoras de fondos de pensiones; las organizaciones deportivas profesionales, regidas por la ley $\mathrm{N}^{0} 20.019$; las cooperativas de ahorro y crédito; las representaciones de bancos extranjeros y las empresas de 
depósito de valores regidas por la ley $N^{0} 18.876$. Todas éstas deberán designar un funcionario responsable de relacionarse con la Unidad de Análisis Financiero.” (Ley 19.913, 2015)

Por otro lado, la ley define como operación sospechosa todo acto, operación 0 transacción que, de acuerdo con los usos y costumbres de la actividad de que se trate, resulte inusual o carente de justificación económica 0 jurídica aparente 0 pudiera constituir alguna de las conductas contempladas en el artículo $8^{\circ}$ de la ley $\mathrm{N}^{0} 18.314$, 0 sea realizada por una persona natural 0 jurídica que figure en los listados de alguna resolución del Consejo de Seguridad de las Naciones Unidas, sea que se realice en forma aislada o reiterada. (Ley 19.913, 2015)

"La comunicación o reporte que se realice, deberá contener información respecto de la(s) operación(es) que se informa(n) y de los involucrados en ella(s), indicando los elementos que se tuvieron en consideración al definir la(s) operación(es) como sospechosa(s). En relación con el cumplimiento de este deber, los sujetos obligados contemplados habrán de designar un funcionario responsable de relacionarse con la Unidad de Análisis Financiero, que suele denominarse "Oficial de Cumplimiento" (Compliance Officer, en inglés) u "Oficial de Prevención de Lavado de Activos" (Anti-Money Laundering Officer, en inglés)." (Toso, 2008; 14)

La segunda obligación aplicable a los sujetos indicados en el artículo 3 de la Ley 19.913, se desprende de lo dispuesto en su artículo 2 b). De acuerdo con esta norma, los sujetos obligados habrán de proporcionar a la UAF los antecedentes que, con ocasión de la revisión de una operación sospechosa detectada por aquella en el ejercicio de sus atribuciones, resulten necesarios y conducentes para desarrollar o completar el análisis de dicha operación o bien a efectos de compartir información con sus similares en el extranjero, en las condiciones señaladas en el artículo 2 g) de la Ley 19.913. (Toso, 2008; 15)

La tercera obligación aplicable a los sujetos obligados es la de “...mantener registros especiales por el plazo mínimo de cinco años, e informar a la Unidad de Análisis Financiero cuándo esta lo requiera, de toda operación en efectivo superior a cuatrocientas cincuenta unidades de fomento o su equivalente en otras monedas". A este respecto, la UAF ha indicado que "Se debe considerar como efectivo, para estos efectos, solo a aquellas operaciones que se materialicen mediante papel moneda o dinero metálico". (Toso, 2008; 15)

\section{Otras medidas de prevención de lavado de activos establecidas en el ordenamiento jurídico chileno}

"Según hemos señalado, nuestro sistema de prevención de lavado de activos se 
completa con el contenido de las circulares emitidas por la Unidad de Análisis Financiero, dictadas en cumplimiento de lo dispuesto en el artículo 2 e) y f) de la Ley 19.913, así como con la regulación proveniente de los organismos supervisores de distintos sectores de la actividad económica nacional. La mayoría de estos instrumentos viene a aclarar ciertos aspectos en relación con la aplicación de las disposiciones contenidas en la Ley 19.913." (Toso, 2008; 17)

Es así con relación a los instrumentos se han dado a conocer mecanismos de orientación 0 ayuda, los cuales no están normados en la ley en estudio pero establecen, medidas de prevención, adicionales a las precedentemente expuestas. En primer lugar, la de conocer a los clientes, conocida como "Know Your Customer o KYC", en inglés. Esta constituye la base de un sistema efectivo antiblanqueo. El cumplimiento adecuado de los deberes de información que impone la Ley 19.913, se encuentra estrechamente relacionado con el conocimiento que los sujetos obligados han de tener respecto de sus clientes. Así, solo será posible calificar una operación como sospechosa de blanqueo, si se cuenta con antecedentes suficientes, tanto de la propia transacción como de quienes participan en ella. Además, para efectuar las comunicaciones correspondientes, se requiere contar con los datos necesarios para sustentarlas, lo que supone un adecuado conocimiento respecto de los clientes y las operaciones que estos llevan a cabo. Se ha señalado que este deber no solo debe concebirse como una herramienta orientada a la prevención, sino que también como un mecanismo de gestión eficaz de los riesgos a los cuales está expuesta una entidad. (Toso, 2008; 19)

"En relación con los elementos constitutivos de una política de conocimiento del cliente, se ha considerado que, una estructura KYC adecuada conlleva, en ciertos casos, el establecimiento de un plan de aceptación de clientes. Además requiere la completa identificación de los mismos y sus actividades, y el seguimiento permanente de las operaciones efectuadas por ellos". (Toso, 2008; 19)

Por otro lado, las entidades bancarias, realizan una distinción entre aquellos clientes que mantienen una cuenta corriente con la institución de aquellos que no la tienen. Ángela Toso en su investigación señala "Si bien respecto de los primeros no se señala expresamente, se puede deducir de la regulación indicada que, en relación con ellos, se ha de cumplir, respecto de su identificación, lo dispuesto en el Capítulo 2.2 de la Recopilación de Normas de la SBIF, referido a cuentas corrientes bancarias y cheques.

Por su parte, la Superintendencia de Valores y Seguros, si bien establece el deber de las entidades sometidas a su fiscalización de “...adoptar como una política rutinaria y propia de su forma de operar un adecuado conocimiento de sus clientes, 
de las actividades generadoras de los recursos utilizados en sus transacciones y de las características más relevantes de las operaciones que estos realizan... "solo se refiere al contenido preciso de dicha obligación cuando se esté en presencia de operaciones en efectivo 0 instrumentos negociables al portador sobre 450 Unidades de Fomento 0 ante una operación sospechosa de lavado de activos. (Toso, 2008; 20)

Otra medida antiblanqueo diseñada, es la de seleccionar adecuadamente y capacitar, en forma permanente, al personal de los sujetos obligados. En este sentido, la UAF ha establecido que se "...debe contemplar el desarrollo y ejecución de programas de capacitación e instrucción permanentes a sus empleados, actividad a la que estos deberán asistir a lo menos una vez al año". En cuanto al contenido de dichos programas, se ha señalado que este debe incluir "...a lo menos, los conceptos de lavado o blanqueo de activos y sus consecuencias, la normativa que regula la materia y sus sanciones tanto administrativas como penales así como, también, las señales de alerta y procedimientos frente a una operación de carácter sospechosa". (Toso, 2008; 25)

"También se contempla, como deber antiblanqueo, el de elaborar manuales de procedimiento frente a una operación sospechosa y códigos de conducta aplicables al personal de los sujetos obligados. Finalmente, se establece como deber de prevención de lavado de activos, el diseño y aplicación de programas de auditoría interna, destinados a evaluar la eficacia del sistema de prevención implementado en la entidad correspondiente." (Toso, 2008; 26)

\section{METODOLOGÍA DE LA INVESTIGACIÓN}

La propuesta metodológica corresponde a una de tipo cualitativo con un alcance de comprehensión, obteniendo los antecedentes necesarios con el fin de lograr analizar el efecto que tiene la implementación de la Ley $N^{\circ} 19.913$ con respecto de lavado y blanqueo de activos, en una institución financiera que resulta obligada por esta ley, a reportar entre otros hechos, las operaciones sospechosas que surgen en las actividades que realiza a diario, todo esto, a través de la realización de entrevistas al agente de sucursal, ejecutivo de cuentas, encargado de operaciones y personal de ventas de la institución en estudio.

\section{ANÁLISIS DE RESULTADOS}

A continuación se presentan los respectivos análisis de los resultados que se 
obtuvieron de las entrevistas efectuadas, tabulados de acuerdo a las categorías de análisis establecidas.

\begin{tabular}{|c|c|c|}
\hline Categoría & \multicolumn{2}{|l|}{ Conclusiones } \\
\hline $\begin{array}{l}\text { Identificación } \\
\text { situaciones } \\
\text { de riesgo }\end{array}$ & \multicolumn{2}{|c|}{$\begin{array}{l}\text { A través del Sistema Operaciones Sensibles surgen alertas preventivas, en donde } \\
\text { éste califica posibles situaciones riesgosas para que sean revisadas por el ejecutivo } \\
\text { del cliente bajo sospecha, como por ejemplo el ingreso de pequeñas cantidades de } \\
\text { dinero, con una frecuencia alta a través de depósitos o transferencias electrónicas } \\
\text { (fraccionamiento de sumas de dinero). Estas alertas surgen de manera automática } \\
\text { en la red y corresponde desde errores del usuario a casos extremos como lavado de } \\
\text { dinero. Pueden surgir alertas de algún cliente, que implique auditorías, revisiones o } \\
\text { información extra. En segunda instancia la identificación de situaciones de riesgos } \\
\text { surge al encontrar inconsistencias en los datos entregados por el cliente luego de } \\
\text { realizar la validación con las herramientas que existe para ello. Las identificaciones } \\
\text { de situaciones de riesgo por lo tanto, es si concuerda o no los datos y validaciones } \\
\text { realizadas. Cabe destacar que desde el área de ventas del banco surge el primer filtro } \\
\text { de potenciales clientes en donde nacen estas situaciones. }\end{array}$} \\
\hline Categoría & $\begin{array}{l}\text { Sub } \\
\text { Categoría }\end{array}$ & Conclusiones \\
\hline $\begin{array}{l}\text { Identificación } \\
\text { Situaciones } \\
\text { de Riesgo }\end{array}$ & $\begin{array}{l}\text { Mecanismos } \\
\text { de Control }\end{array}$ & $\begin{array}{l}\text { En primer lugar, todos los documentos y datos que el cliente } \\
\text { entrega, son analizados para asegurar su validación. Dentro del } \\
\text { control realizado está la validación de la correcta confección de } \\
\text { las liquidaciones de sueldo, la vigencia del carnet de identidad, } \\
\text { así como también la aplicación de los descuentos previsionales } \\
\text { de salud y/o afp según la institución. Luego corresponde realizar } \\
\text { una verificación de domicilios, laboral y particular, además de la } \\
\text { realización de llamados para confirmarlos. La solicitud de mantener } \\
\text { por parte del cliente la información vigente y actualizada es otro } \\
\text { mecanismo de control utilizado. Y por último, existe una unidad } \\
\text { que monitorea todas las operaciones que se realizan en el banco } \\
\text { por sus clientes a diario. Uno de los mecanismos más certeros } \\
\text { a hora de analizar la información, es una matriz Excel, en donde } \\
\text { deben cuadrar las liquidaciones de sueldo, como por ejemplo los } \\
\text { montos de los impuestos. En caso de no poseer liquidaciones, } \\
\text { las boletas de honorarios son chequeadas a través de la página } \\
\text { del Servicio de Impuestos Internos, y así saber si los documentos } \\
\text { son reales o no. Existen otros casos donde corresponde utilizar } \\
\text { mecanismos de control importantes, como es el de las inversiones, } \\
\text { depósitos a plazo, fondos mutuos o algún otro tipo de ahorro, } \\
\text { que algún cliente quisiera realizar por medio del banco, en este } \\
\text { caso, si son montos superiores a \$5.000.000 se deben presentar } \\
\text { declaraciones del origen de estos fondos, así como todos los } \\
\text { documentos que respalden la transacción que originó la suma } \\
\text { de dinero. Cabe destacar, que las transacciones además deben } \\
\text { haber sido autorizadas por personal de operaciones del banco. } \\
\text { Operaciones también supervisa que las carpetas contengan todos } \\
\text { los documentos solicitados, el formulario KYC, y la legitimidad de } \\
\text { las firmas realizadas; ya sea por posibles situaciones de riesgo } \\
\text { como el surgimiento de auditorías repentinas. }\end{array}$ \\
\hline
\end{tabular}




\begin{tabular}{|c|c|c|}
\hline Categoría & $\begin{array}{l}\text { Sub } \\
\text { Categoría }\end{array}$ & Conclusiones \\
\hline \multirow[t]{4}{*}{$\begin{array}{l}\text { Identificación } \\
\text { Situaciones } \\
\text { de Riesgo }\end{array}$} & $\begin{array}{l}\text { Herramientas } \\
\text { utilizadas }\end{array}$ & $\begin{array}{l}\text { Dentro de la utilización de herramientas en la identificación de } \\
\text { situaciones de riesgo, los entrevistados comentaron que existen las } \\
\text { siguientes: } \\
\text { - SOS - Sistema operaciones sensibles, corresponde a una } \\
\text { herramienta que está orientada a advertir sobre alertas preventivas, } \\
\text { pertenece a un departamento especial del banco. } \\
\text { - Matriz de validación de las liquidaciones de sueldo, es una planilla } \\
\text { Excel que sirve para encontrar inconsistencia en las liquidaciones. } \\
\text { - Informe verificador de domicilios (externo) para asegurar domicilio } \\
\text { de los clientes y efectuar posteriores pagos. } \\
\text { - Declaración de orígenes de fondos, es un formulario que sirve } \\
\text { para detectar qué tipo de transacción u operación desea realizar el } \\
\text { cliente como también la procedencia del dinero. }\end{array}$ \\
\hline & $\begin{array}{l}\text { Solicitud de } \\
\text { Documentos } \\
\text { a revisar }\end{array}$ & $\begin{array}{l}\text { Los documentos que corresponde solicitar son principalmente } \\
\text { liquidaciones de sueldo, cotizaciones y carnet de identidad, para } \\
\text { respaldar la situación económica o personal de los potenciales } \\
\text { clientes de la institución bancaria, por lo tanto, es menester } \\
\text { presentarlos y validar su legitimidad. Estos documentos son } \\
\text { solicitados para todas las personas, ya sean clientes nuevos } 0 \\
\text { vigentes del banco, ya que estos últimos podrían tener variaciones } \\
0 \text { modificaciones en los datos entregados en un principio } 0 \\
\text { anteriormente en alguna otra solicitud. Solamente el banco hace la } \\
\text { diferencia en el tipo de documentos a solicitar según la calidad del } \\
\text { cliente, es decir, si éste corresponde a un trabajador dependiente } 0 \\
\text { independiente. }\end{array}$ \\
\hline & $\begin{array}{l}\text { Documentos } \\
\text { Cliente } \\
\text { Dependiente }\end{array}$ & $\begin{array}{l}\text { Los documentos a presentar si corresponde a un trabajador } \\
\text { dependiente son: } 3 \text { últimas liquidaciones de sueldo o pensión, } 12 \\
\text { últimas cotizaciones de AFP, contrato de trabajo, si tiene vehículo a } \\
\text { su nombre: permiso de circulación, si tiene propiedad a su nombre: } \\
\text { último pago contribución o pago de derecho de aseo, acreditación } \\
\text { de pagos otras instituciones, estudios: certificado de título/ } \\
\text { diploma, cédula de identidad, acreditación de ahorro para compra } \\
\text { de propiedad }\end{array}$ \\
\hline & $\begin{array}{l}\text { Documentos } \\
\text { Cliente } \\
\text { Independiente }\end{array}$ & $\begin{array}{l}\text { Los documentos a presentar si corresponde a un trabajador } \\
\text { independiente son: } 2 \text { últimas declaraciones de impuesto, } 6 \text { últimos } \\
\text { meses de boletas de honorarios, si tiene giro, los últimos } 12 \text { IVA, } \\
\text { acreditación de permiso de circulación vehículo, acreditación de } \\
\text { escritura por propiedad, acreditación de pagos otras instituciones, } \\
\text { cédula de identidad, acreditación de estudios. }\end{array}$ \\
\hline
\end{tabular}




\begin{tabular}{|c|c|c|}
\hline Categoría & \multicolumn{2}{|l|}{ Conclusiones } \\
\hline $\begin{array}{l}\text { Mecanismos } \\
\text { para prevenir } \\
\text { delito de } \\
\text { lavado de } \\
\text { activos }\end{array}$ & \multicolumn{2}{|c|}{$\begin{array}{l}\text { Según los entrevistados acá juegan todas las herramientas utilizadas en la categoría } \\
\text { anterior, ya que apuntan a la eficacia en la validación de clientes sospechosos. } \\
\text { Los mecanismos para prevenir el delito de lavado de activos son utilizados a } \\
\text { diario en todos los tipos de transacciones que se realizan en el banco, como por } \\
\text { ejemplo, surge una alerta inmediata si algún cliente llega con montos grandes de } \\
\text { dinero. Pueden surgir alertas desde Santiago (Casa matriz) por posible operación } \\
\text { sospechosa, las cuales son enviadas a través de la red. }\end{array}$} \\
\hline Categoría & Sub Categoría & Conclusiones \\
\hline \multirow[t]{6}{*}{$\begin{array}{l}\text { Mecanismos } \\
\text { para prevenir } \\
\text { delito de } \\
\text { lavado de } \\
\text { activos }\end{array}$} & $\begin{array}{l}\text { Relación } \\
\text { con clientes } \\
\text { sospechosos }\end{array}$ & $\begin{array}{l}\text { Si la validación realizada identifica riesgos probables de la } \\
\text { relación con clientes sospechosos, el banco se reserva el } \\
\text { derecho a admitir a una persona como cliente o no, obviamente } \\
\text { luego de realizar los controles pertinentes, evaluaciones y } \\
\text { teniendo toda la información de respaldo. Se debe contactar al } \\
\text { cliente mediante el ejecutivo comercial de la manera más formal } \\
\text { posible y realizar consultas sin dar mayores explicaciones } \\
\text { acerca de que si está realizando alguna transacción o si necesita } \\
\text { algún tipo de ayuda. También existen instancias para solicitar } \\
\text { nuevas validaciones o realizarlas en caso de que no la hayan } \\
\text { hecho, por parte de operaciones. }\end{array}$ \\
\hline & $\begin{array}{l}\text { Procedimiento a } \\
\text { realizar }\end{array}$ & $\begin{array}{l}\text { El banco entrega una respuesta políticamente correcta, en donde } \\
\text { se le explica a la persona que no califica, al no cumplir con los } \\
\text { requisitos que el banco solicita. En caso que correspondan a } \\
\text { clientes ya ingresados en el sistema y se corrobora la sospecha } \\
\text { de algún delito, se bloquea la cuenta corriente del cliente hasta } \\
\text { tener claridad del asunto desde un punto de vista legal. }\end{array}$ \\
\hline & $\begin{array}{l}\text { Trabajadores } \\
\text { sospechosos }\end{array}$ & $\begin{array}{l}\text { La manera de identificar es a través del agente del banco, el } \\
\text { cual debiera lograr darse cuenta de la posible falta. El área de } \\
\text { operaciones puede solicitar nuevos antecedentes o nuevas } \\
\text { firmas en caso de sospecha. }\end{array}$ \\
\hline & $\begin{array}{l}\text { Procedimientos } \\
\text { a realizar }\end{array}$ & $\begin{array}{l}\text { Los procedimientos a realizar nacen con la realización de } \\
\text { controles minuciosos e investigaciones posteriores por parte } \\
\text { del agente del banco, como por ejemplo, si es necesaria la } \\
\text { suspensión de funciones del funcionario. }\end{array}$ \\
\hline & $\begin{array}{l}\text { Posibilidad de } \\
\text { cometer delitos } \\
\text { por parte de la } \\
\text { institución }\end{array}$ & $\begin{array}{l}\text { La posibilidad de que el banco se viera afectado por la comisión } \\
\text { de algún delito es parte del riesgo del negocio, sobretodo por } \\
\text { la connotación que tiene el dinero en general, por lo tanto la } \\
\text { institución trata de minimizar el que puedan ingresar clientes } \\
\text { que estén intentando lavar dinero y así cometer por parte del } \\
\text { banco delitos de esta índole, en donde, por ejemplo pueda } \\
\text { servir de intermediario y facilitar el delito. Los protocolos de } \\
\text { seguridad al ser cumplidos indica que no debieran existir este } \\
\text { tipo de problemas, ya que las faltas que se cometen son contra } \\
\text { la Superintendencia asociados a protocolos no cumplidos. }\end{array}$ \\
\hline & $\begin{array}{l}\text { Mecanismos } \\
\text { de Control } \\
\text { estandarizados }\end{array}$ & $\begin{array}{l}\text { Al presentar cualquier opción a invertir hay mínimos de dinero } \\
\text { en que se solicitan declaraciones extras, en donde el cliente } \\
\text { debe indicar la procedencia de los fondos, como también la } \\
\text { emisión de vales vistas menores a montos determinados. }\end{array}$ \\
\hline
\end{tabular}




\begin{tabular}{|c|c|c|}
\hline Categoría & \multicolumn{2}{|l|}{ Conclusiones } \\
\hline $\begin{array}{l}\text { Cumplimiento } \\
\text { de la Ley }\end{array}$ & \multicolumn{2}{|c|}{$\begin{array}{l}\text { Los entrevistados mencionaron si el banco en general cumple con las } \\
\text { obligaciones descritas en la ley } 19.913 \text {, con respecto al lavado de dinero, al } \\
\text { ser una entidad que resulta obligada a informar operaciones sospechosas que } \\
\text { adviertan en el ejercicio de sus actividades. }\end{array}$} \\
\hline Categoría & Sub Categoría & Conclusiones \\
\hline \multirow[t]{9}{*}{$\begin{array}{l}\text { Cumplimiento } \\
\text { de la Ley }\end{array}$} & $\begin{array}{l}\text { Capacitación e } \\
\text { instrucción al } \\
\text { personal }\end{array}$ & $\begin{array}{l}\text { Se realizan de una a dos veces al año. Constan de reuniones } \\
\text { en la zona donde asiste todo el personal de la institución } \\
\text { independiente de la sucursal y de las distintas áreas. Éstas son } \\
\text { evaluadas. }\end{array}$ \\
\hline & $\begin{array}{l}\text { Temas } \\
\text { tratados en } \\
\text { capacitaciones }\end{array}$ & $\begin{array}{l}\text { Los temas incluidos en las capacitaciones son netamente } \\
\text { de lavado de dinero, ya sean definiciones, leyes aplicadas, } \\
\text { ejemplos, mecanismos de prevención y detección }\end{array}$ \\
\hline & $\begin{array}{l}\text { Manuales de } \\
\text { procedimientos }\end{array}$ & $\begin{array}{l}\text { Se encuentran en la intranet del banco con sistemas de } \\
\text { seguridad para que no puedan ser expuestos a personas } \\
\text { externas que luego puedan quebrantar la seguridad de los } \\
\text { procedimientos }\end{array}$ \\
\hline & $\begin{array}{l}\text { Programas de } \\
\text { auditoría }\end{array}$ & $\begin{array}{l}\text { Las auditorías son realizadas de dos formas, una con muestra } \\
\text { al azar, en donde se solicitan carpetas de clientes para evaluar } \\
\text { las operaciones y para validar la información presentada. Estas } \\
\text { corresponden a auditorías sin avisar. Y otra a nivel general } \\
\text { en donde se evalúan todas las áreas: persona, empresa, } \\
\text { operaciones y comercial. La idea es que las propuestas sean } \\
\text { evaluadas e informadas. En el área de operaciones también se } \\
\text { realizan auditorias, estas son independientes por área. Ahí se le } \\
\text { revisan todos los procesos, movimientos de caja, acreditación } \\
\text { de los orígenes de fondos, entre otras. }\end{array}$ \\
\hline & $\begin{array}{l}\text { Frecuencia con } \\
\text { que se realiza }\end{array}$ & $\begin{array}{l}\text { Una vez al mes enviando información a Santiago de carpetas } \\
\text { al azar de clientes nuevos o no y una vez al año de manera } \\
\text { presencial en la sucursal }\end{array}$ \\
\hline & $\begin{array}{l}\text { Sistema de } \\
\text { Identificación de } \\
\text { clientes }\end{array}$ & $\begin{array}{l}\text { Utilizan el "KYC - Know your costumer" para todas las } \\
\text { operaciones. Cada solicitud nueva incluye la actualización } \\
\text { de este formulario en donde se detalla todo para conocer al } \\
\text { cliente, como lo indica su sigla en inglés (conozca su cliente). } \\
\text { De acuerdo al conocimiento del cliente nace este documento. }\end{array}$ \\
\hline & KYC & $\begin{array}{l}\text { Consiste en un formulario en donde el ejecutivo completa los } \\
\text { campos con datos del cliente para un mejor conocimiento de } \\
\text { éste. Incluye datos como qué productos posee, renta, etc. Es } \\
\text { un resumen completo de toda la información de los clientes. }\end{array}$ \\
\hline & $\begin{array}{l}\text { Reporte } \\
\text { operaciones } \\
\text { sospechosas }\end{array}$ & $\begin{array}{l}\text { El reporte de operaciones sospechosas se realiza a través del } \\
\text { sistema "SOS" generando alertas preventivas, las que llegan } \\
\text { a instancias de calificación sospechosa son tratadas por un } \\
\text { departamento especial que se comunica con la UAF a través de } \\
\text { procedimientos estrictos. }\end{array}$ \\
\hline & $\begin{array}{l}\text { Entrega } \\
\text { antecedentes a } \\
\text { la UAF }\end{array}$ & $\begin{array}{l}\text { Quien se encarga de la entrega de antecedentes a la Unidad de } \\
\text { Análisis Financiero es el área de SOS, además de mantener los } \\
\text { registros importantes por el mínimo de años que requiere la ley. }\end{array}$ \\
\hline
\end{tabular}




\begin{tabular}{|l|l|l|}
\hline Categoría & Sub Categoría & Conclusiones \\
\hline $\begin{array}{l}\text { Cumplimiento } \\
\text { de la Ley }\end{array}$ & $\begin{array}{l}\text { Mantenimiento } \\
\text { de Registros }\end{array}$ & $\begin{array}{l}\text { Los registros de los clientes como sus carpetas son mantenidas } \\
\text { en la sucursal por el periodo que dure la relación comercial, si } \\
\text { son clientes rechazados, las carpetas son mantenidas por lo } \\
\text { menos dos años en la sucursal. Posteriormente son enviadas } \\
\text { a bodegas. }\end{array}$ \\
\cline { 2 - 3 } & $\begin{array}{l}\text { Procedimientos } \\
\text { especiales }\end{array}$ & $\begin{array}{l}\text { En el banco, para las operaciones que superen los } \$ 5.000 .000 \\
\text { se solicita una declaración del origen de fondos, para tener un } \\
\text { respaldo de la procedencia de esos dineros. }\end{array}$ \\
\cline { 2 - 4 } & $\begin{array}{l}\text { Encargado } \\
\text { u Oficial de } \\
\text { cumplimiento }\end{array}$ & $\begin{array}{l}\text { El banco como matriz consta con aproximadamente 10 } \\
\text { oficiales de cumplimiento que están destinados a cubrir las } \\
\text { necesidades de las distintas zonas del país. }\end{array}$ \\
\cline { 2 - 3 } & $\begin{array}{l}\text { Labor del oficial } \\
\text { de cumplimiento }\end{array}$ & $\begin{array}{l}\text { Se encarga de resolver inconvenientes que en la sucursal } \\
\text { como unidad no ha podido resolver, además de reportar las } \\
\text { operaciones a la UAF. En la sucursal se encarga de validar las } \\
\text { transacciones y la acreditación de ellas. }\end{array}$ \\
\hline
\end{tabular}

\section{DISCUSIÓN DE RESULTADOS}

Al efectuar la presente investigación se logra corroborar la información contenida en la teoría de sustento presentada, es decir, el marco teórico concuerda con la información obtenida a través de la recopilación de datos.

Como fue mencionado por Ángela Toso (2008) uno de los hechos que marcan la posibilidad de encontrarse con el lavado de dinero, es que surge la obligación para quienes cometen este delito, tratar de encontrar las vías que le permitan introducir al circuito monetario las cantidades de dinero de origen ilícito, para obtener una rentabilidad sin justificar su procedencia, lo que concuerda con lo explicado por los entrevistados, al mencionar que una manera de identificar situaciones de riesgo, es el llamado fraccionamiento de sumas de dinero, por lo que surge como una identificación de situaciones de riesgo, las alertas presentadas por un sistema de protección que tiene el banco, en donde advierte acerca de un aumento de transacciones que puede corresponder a lo ya mencionado. Dentro de este contexto y también mencionado por Toso en su investigación, en los métodos de colocación, la presentación de documentos falsos para enmascarar el origen o titularidad de los fondos, lo que para la institución financiera en estudio corresponde a una de las situaciones a controlar a través de los mecanismos de control: la validación de toda la información presentada en las solicitudes de productos financieros; mediante las herramientas establecidas para ello, como el informe verificador de domicilio, declaración de orígenes de fondo, matriz de validación y el sistema de operaciones sospechosas.

En relación a las categorías de análisis, es necesario mencionar que en un 
principio la categoría de identificación de situaciones de riesgo se subdividía en las subcategorías de mecanismo de control, solicitud de documentos a revisar y clientes que no posean cuentas corrientes, sin embargo luego de la obtención de resultados los entrevistados dejaron en evidencia que ellos no hacían distinción alguna en la solicitud de documentos a clientes que ya formaban parte del banco y que solo distinguían aquellos clientes dependientes de los independientes, por lo tanto, las subcategorías de análisis de la categoría ya mencionada está compuesta por mecanismo de control y solicitud de documentos a revisar, ésta última subdividiéndose en documentos cliente dependiente y documentos cliente independiente. En general está compuesta por las liquidaciones de sueldo, certificado de cotizaciones y carnet de identidad.

Las alertas que surgen desde el departamento de operaciones sensibles (SOS) que corresponde a una herramienta utilizada en la identificación de situaciones de riesgo, donde surgen alertas por alta cantidad de transacciones o movimientos sospechosos en transferencias bancarias, concuerdan a una de las presentadas por Ecured en las maneras de utilizar actividades licitas para ocultar el origen ilícito de recursos: Movimiento de dinero a través del sistema financiero, utilizando los productos y tecnologías ofrecidas por el sector financiero. (Ecured, 2009). Estas alertas surgen como respuestas al peligro de este tipo de actividades.

Uno de mecanismos de prevención del lavado de activos mencionados por la Superintendencia de Bancos e Instituciones Bancarias, la auditoría, forma parte en las actividades que realiza el banco en este proceso de prevención ya que toma importancia tanto sus procedimientos como la frecuencia con que son realizadas. La institución financiera en estudio señala que este mecanismo es realizado en distintas oportunidades del año comercial, haciendo diferencias en auditorías presenciales una vez al año y auditorias desde distancia, mensuales.

Como ya se mencionó, el banco hace diferencia en los potenciales clientes y clientes en función del tipo de trabajador al que corresponde, si es trabajador dependiente 0 independiente, es por eso, que los documentos a solicitar para ser revisados varía según el caso, los cuales ingresan al proceso de validación y primer filtro frente a operaciones y/o clientes sospechosos.

Dentro de la categoría mecanismos para prevenir delito de lavado de activos se distinguen 3 situaciones, la primera en relación a la posibilidad de relacionarse con personas sospechosas, la segunda, encontrarse con personal del banco que resulte sospechosa, y por último, si el banco puede cometer los delitos. Los entrevistados fueron determinantes en decir que el banco tiene la capacidad de decidir el tipo de gente con que se relaciona o de terminar contratos con personas sospechosas, 
por lo tanto posee procedimientos especiales al igual que en la segunda situación. Con respecto a que la posibilidad de cometer delitos por parte de la institución las respuestas fueron positivas, ya que se entiende el riesgo del negocio en que se encuentra. Como fue mencionado por Toso en su investigación advirtiendo acerca del rubro bancario, establecimientos financieros, casas de cambio u otros tipos de negocios de muy variada condición en donde se podía trasladar materialmente el dinero.

El cumplimiento de la Ley corresponde al de las obligaciones descritas en los distintos artículos de la Ley 19.913 de lavado de dinero, en donde luego de nombrar las entidades que resultan obligadas además indica cuáles son estas obligaciones. Se consultó si la institución cumple principalmente con capacitaciones e instrucciones al personal, posee manuales de procedimientos frente a operaciones sospechosas, realiza programas de auditorías, también como identifican a sus clientes, el reporte de operaciones sospechosas, si entregan antecedentes a la UAF, si posee encargado u oficial de cumplimiento y por último, si identifican procedimientos especiales.

También la UAF hace referencia al reporte de operaciones en efectivo (ROE), el cual fue modificado ampliando el rango de 450 UF a USD 10.000. Si bien, en el banco entienden la importancia del monto de la transacción, ellos colocan mayor control en dichas situaciones tomando en consideración un monto menor al que la ley menciona y obliga a reportar. El banco en este caso, cuenta con procedimientos especiales estandarizados para esos casos, como por ejemplo la solicitud al cliente de una declaración de orígenes de fondos.

Respecto al sistema de identificación de clientes, utilizan un instrumento común no normado por la ley, que es el "Know Your Customer o KYC". "Esta constituye la base de un sistema efectivo antiblanqueo". (Toso, 2008; 19) Consiste en un formulario que todos los clientes deben poseer en sus carpetas, debidamente completado por su ejecutivo y sirve de base para adquirir conocimiento respecto del cliente.

Como se plantea en el marco teórico la prevención del lavado de dinero según Toso, tiene como obligación según la Ley 19.913, designar un funcionario responsable de relacionarse con la Unidad de Análisis Financiero, que suele denominarse "Oficial de Cumplimiento" u "Oficial de Prevención de Lavado de Activos" (Toso, 2008; 14) Con respecto a esto, el banco posee dentro de la red de sucursales, los que corresponden a 10 personas aproximadamente; son escogidos por su cargo de Jefe de Operaciones y ellos se encargan de reportar todas las situaciones sospechosas a la UAF. 


\section{CONCLUSIONES}

Luego de efectuar los respectivos análisis y discusiones de los resultados obtenidos, es posible exponer las conclusiones que dan cumplimiento a los objetivos planteados al inicio de la investigación.

A través de la recopilación de antecedentes mediante las entrevistas realizadas, se logra identificar situaciones de riesgo en las actividades de la institución financiera, que pudieran resultar inusuales 0 carentes de justificación económica 0 jurídica como es el lavado de dinero, la principal situación de riesgo corresponde al fraccionamiento de sumas de dinero por parte del cliente, del cual no se sabe en su totalidad de la procedencia, estas son advertidas a través del sistema de operaciones sospechosas SOS que cuenta la entidad, la cual también sirve para detectar cantidad de consultas que tiene un rut en el sistema. Otra situación identificada es la de inconsistencias en los datos que son presentados por el cliente, debido a documentos falsos o de poca credibilidad, éstas son detectadas luego del proceso de validación de información que hacen los ejecutivos a través de las herramientas como la matriz de validación, el informe verificador de domicilio, la declaración de orígenes de fondo, el formulario KYC, entre otros.

Con respecto a los mecanismos establecidos para prevenir relacionarse con personas que cometen delitos mencionados en la Ley y su aplicación en la institución financiera, se encuentran con distintos procedimientos, como la validación de datos y/o documentos presentados, verificaciones de domicilio laboral y personal de los clientes, estudios de las liquidaciones de sueldo a través de la matriz Excel que determina correctos descuentos y porcentajes, cabe destacar la solicitud de documentos actualizados de los clientes antiguos del banco para resguardar la mantención de la información en el tiempo. En relación a procedimientos operacionales, se suma a estos mecanismos, el control extra de transacciones con determinados montos "sospechosos" y las revisiones y autorizaciones de los altos mandos del sector operacional y agentes de la sucursal.

De acuerdo a los artículos estudiados de la Ley 19.913 y a las respuestas de los entrevistados, se verifica la aplicación de la ley en lo que respecta al cumplimiento de las obligaciones allí descritas, ya que tienen establecido procesos para ello, como por ejemplo el nombramiento de un oficial o encargado de cumplimiento, resguardo de documentos por el mínimo de años, entre otras.

De acuerdo a lo planteado por la Unidad de Análisis Financiero acerca de solicitar a los sujetos obligados los antecedentes que resulten necesarios frente a una revisión de operación sospechosa, la institución cumple este numeral a través de 
un departamento encargado de relacionarse con la UAF y dar cumplimiento a todos los requisitos que se le proponen, por lo tanto, respecto al reporte de operaciones sospechosas, el oficial de cumplimiento se encarga cumplir las obligaciones descritas en la Ley. Las comunicaciones o reportes a la UAF enviados desde el departamento de prevención de lavado de dinero de la institución financiera, bajo la mirada del personal tiene como propósito cumplir con las expectativas, ya que demuestran la importancia del cumplimiento de las obligaciones y la seguridad que entregan como institución, ya que si bien les afecta directamente, es más importante la imagen que entrega la institución y la transparencia.

La obligación de mantener registros especiales por el plazo mínimo de cinco años, se cumple en su totalidad, ya que los registros de clientes son mantenidos en las sucursales y guardados en bodegas cuando su antigüedad es mayor a la del plazo. Al respecto de informar a la Unidad de Análisis Financiero cuándo esta lo requiera, de toda operación en efectivo superior a diez mil dólares o su equivalente en otras monedas, surge una situación especial, debido a que si bien estas si son informadas, toman mayores precauciones como lo es la declaración de orígenes de fondo.

Con respecto al seleccionar adecuadamente y capacitar, en forma permanente, al personal de los sujetos obligados, el banco realiza programas de capacitación e instrucción a sus empleados una vez al año, cumpliendo a cabalidad con lo normado en la ley. En cuanto al contenido de dichos programas, consisten en conceptos de lavado o blanqueo de activos, leyes involucradas, maneras de prevenir y temas relacionados. En relación a la elaboración de manuales de procedimientos frente a una operación sospechosa, ellos se indican en plataformas de internet, que tienen ciertas restricciones de acceso para que estas no sean vulneradas. Los programas de auditoría interna, destinados a evaluar la eficacia del sistema de prevención implementado en la entidad correspondiente son realizados en distintas instancias, todas ellas con el objetivo de que se cumplan los mecanismos establecidos para que no se vea afectado el normal funcionamiento del negocio.

Por lo tanto, según lo mencionado por el personal del banco del cumplimiento de la ley por parte de la institución, se logra determinar la correcta implementación de ésta en sus labores y del cumplimiento en su totalidad de las obligaciones allí descritas.

Y por último, según el análisis realizado por cada objetivo específico y discusión de los resultados obtenidos ha permitido analizar el efecto de la Ley 19.913 con sus posteriores modificaciones en las operaciones diarias que realiza una institución financiera de la quinta región, en relación al resguardo de la comisión del delito de 
lavado de dinero. Cabe destacar la importancia de este delito en las operaciones que el banco realiza, teniendo en cuenta todos los procesos relacionados como auditorías especiales, capacitaciones con cierta frecuencia, controles extras para determinar procedencia de los dineros, etc. En general no se puede hablar de efectos con importancia económica, ya que si bien la aplicación de la ley involucra mayor cantidad de horas hombres, subvención de las mismas capacitaciones, inducciones y auditorias, son situaciones que el banco tiene considerado invertir, debido al riesgo al que está involucrado el negocio. Para ellos es más importante la imagen que entregan como institución bancaria y la seguridad que entregan a sus clientes, por lo mismo se preocupan de escoger a personas con estándares establecidos, sin dejar de cumplir con la legislación chilena. 


\section{BIBLIOGRAFÍA}

- Cano \& Lugo, (2005) "Auditoría forense en la investigación criminal del lavado de dinero y activos". Ecoe Ediciones. Bogotá

- Dawes y Villanueva (2010) "Control y prevención de lavado de dinero". PWC. Santiago, Chile

- Financial Action Task Force (GAFI). Disponible en: http://www.fatt-gafi. org/

- Gobierno de Chile, Unidad de Análisis Financiero. Disponible en: www. uaf.cl

- Gómez, (1997) "El auditor frente al lavado de dinero". Universidad Católica del Norte, Chile.

- Ley № 19.913. Diario Oficial de la República de Chile, Santiago, Chile, 30 de junio de 2003.

- Ministerio de Justicia y Derechos Humanos, Unidad de Información Financiera, Buenos Aires. Última actualización mayo del 2015. Disponible en: http://www.uif.gov.ar/uif/index.php/es/

- Rocha, R. (2000) "La economía colombiana tras 25 años de narcotráfico". Siglo de hombre Editores. Colombia.

- Superintendencia de Bancos e Instituciones Financieras, Circular $n^{\circ}$ 3435,2008

- Toso, A. (2008) "Blanqueo de capitales su prevención en el ordenamiento jurídico chileno". Revista Chilena de Derecho. Chile 